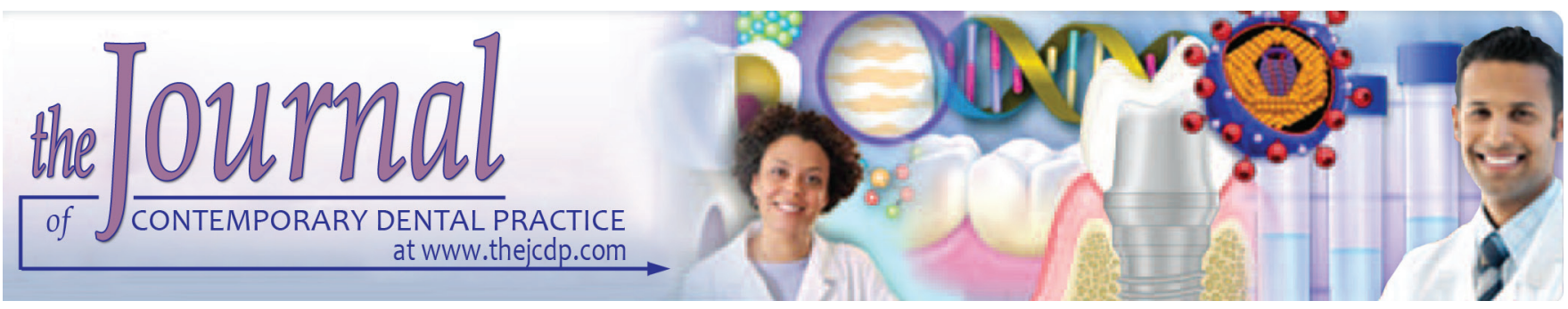

\title{
Long-term Retrospective Study based on Implant Success Rate in Patients with Risk Factor: 15-year Follow-up
}

\author{
${ }^{1}$ Baburajan Kandasamy, ${ }^{2}$ Navleen Kaur, ${ }^{3}$ Gulshan K Tomar, ${ }^{4}$ Atul Bharadwaj, ${ }^{5}$ Litto Manual, ${ }^{6}$ Meghna Chauhan
}

\begin{abstract}
Aim: The purpose of this retrospective study is to assess implant success rates with various risk factors.
\end{abstract}

Materials and methods: Two hundred patients with a total of 650 implants were selected. Risk factors, such as smoking, antidepressants, bruxism, diabetes, and bone augmentation procedures were considered, and patients were followed up for a period of 8 to 15 years.

Results: Of 650 implants placed, the success rate was $88 \%$, i.e., a total of 572 implants were successful. A total of 78 implants were considered failure; and out of 78 , twenty implants were surgically removed.

Conclusion: Based on this study's results, it is concluded that risk factors, such as smoking, bruxism, diabetes, and bone augmentation play an important role in success rate of dental implants.

Clinical significance: Several factors, such as bruxism, diabetes, and supporting bone can play an important role in dental implant success.

Keywords: Bone height, Bruxism, Dental implant, Diabetes, Failure, Smoking.

\footnotetext{
${ }^{1}$ Department of Prosthodontics, PSI Dental College, Madurai Tamil Nadu, India

${ }^{2}$ Department of Prosthodontics, Genesis Institute of Dental Sciences \& Research, Ferozpur, Punjab, India

${ }^{3}$ Department of Prosthodontics, Uttaranchal Dental \& Medical Research Institute, Dehradun, Uttarakhand, India

${ }^{4}$ Department of Prosthodontics, College of Dental Sciences Majmaah University, Al Majmaah, Kingdom of Saudi Arabia

${ }^{5}$ Department of Prosthodontics, Al-Azhar Dental College Thodupuzha, Kerala, India

${ }^{6}$ Department of Prosthodontics, Mallareddy Institute of Dental Sciences, Hyderabad Telangana, India

Corresponding Author: Navleen Kaur, Department of Prosthodontics, Genesis Institute of Dental Sciences \& Research, Ferozpur, Punjab, India, e-mail: navleenanand18@ gmail.com
}

How to cite this article: Kandasamy B, Kaur N, Tomar GK, Bharadwaj A, Manual L, Chauhan M. Long-term Retrospective Study based on Implant Success Rate in Patients with Risk Factor: 15-year Follow-up. J Contemp Dent Pract 2018;19(1):90-93.

Source of support: Nil

Conflict of interest: None

\section{INTRODUCTION}

Dentition in human includes primary or permanent dentition. Aging is a natural process and as age advances there comes a stage of incomplete dentition, i.e., missing teeth. Holm-Pedersen and Loe ${ }^{1}$ reported that more than $50 \%$ of the elderly populations are edentulous in industrialized society. Being edentulous not only affects the person functionally, i.e., difficulty in eating and speech, but it can also lead to psychological problems due to low self-esteem in society. One of the best ways for rehabilitation of the incomplete dentition is by osseointegrated dental implants therapy, as it provides the advantage of conserving the residual dentition and prevents the use of removable appliances.

Implant material should be biologically acceptable to the body and should not evoke body's immune response. Implants consist of three parts: First being the osseous part which interacts with the bone, second is transmucosal components that interact with mucosa, and third is restoration. A 95 to $98 \%$ success rate has been reported in the literature. ${ }^{2}$ Selection of patients and clinical and laboratory phases play a major role in success of implant therapy. Various risk factors, such as smoking, bruxism, periodontal disease, diabetes, bone density, bone augmentation, and implant design affect the success rate of implants. ${ }^{3,4}$ Hence, the aim of our retrospective study is to assess the implant success rates with various risk factors. 
Study based on Implant Success Rate in Patients with Risk Factor

\begin{tabular}{ll}
\hline & Table 1: Patient's demographic value \\
\hline Mean age & $20-70$ years \\
& 47.5 years \\
Males & 88 \\
Females & 112 \\
Jaws & \\
Maxilla & 100 \\
Mandible & 100 \\
Prosthesis & \\
Removable & 15 \\
Fixed & 185 \\
\hline
\end{tabular}

\section{MATERIALS AND METHODS}

Two hundred patients aged between 20 and 70 years with a total of 650 implants were selected based on specific inclusion and exclusion criteria. Follow-up period for the study was 8 to 15 years.

\section{Inclusion Criteria and Exclusion Criteria}

- Patients with implant treatment, who had age $\geq 20$ years were included.

- Patients with single or multiple risk factors, such as smoking, bruxism, periodontal disease, and diabetes were included in this study.

- Patients who have undergone bone augmentation procedure were excluded.

- Medically compromised patients were excluded.

- Patients with history of any psychiatric disorder were excluded.

Two hundred patients who meet inclusion and exclusion criteria were divided into six groups.

1. Group A: Smoking

2. Group B: Bruxism

3. Group C: Periodontal disease

4. Group D: Diabetes

5. Group E: Bone augmentation

6. Group F: Bone height.

In patients with multiple risk factors, groups were divided as $\mathrm{AB}, \mathrm{ABC}, \mathrm{ABCD}, \mathrm{BD}$, etc.

Written consent was obtained from patients before treatment. Treatment was performed in two phases.

1. Phase 1-surgical phase: Prophylactic antibiotic was given to the patient 1 hour before surgery. Guidelines and instruction as provided by the manufacturer were followed.

2. Phase 2-the second phase was performed after 3 to 6 months. Either fixed single or multiple crowns, both screw-retained and cemented-retained, were performed followed by removable overdentures.

Patients were analyzed based on Schnitman and Shulman ${ }^{5}$ success criteria.

- Mobility $<1 \mathrm{~mm}$ in any direction.

Table 2: Analysis of single risk factors

\begin{tabular}{|c|c|c|c|c|c|c|}
\hline Groups & Patients & Implants & $\begin{array}{l}\text { Early } \\
\text { failure }\end{array}$ & $\begin{array}{l}\text { Late } \\
\text { failure }\end{array}$ & $\begin{array}{l}\text { Success } \\
(\%)\end{array}$ & $p$-value \\
\hline A & 20 & 78 & 8 & 2 & 87.17 & 0.004 \\
\hline B & 18 & 55 & 7 & 1 & 85.45 & 0.004 \\
\hline C & 10 & 42 & 3 & 1 & 90.47 & 0.314 \\
\hline D & 10 & 40 & 5 & - & 87.5 & 0.423 \\
\hline$E$ & 14 & 62 & 1 & - & 98.38 & 0.238 \\
\hline $\mathrm{F}$ & 12 & 30 & 4 & 2 & 86.6 & 0.319 \\
\hline Total & 84 & 307 & 28 & 6 & 88.8 & 0.414 \\
\hline
\end{tabular}

- Radiographically observed radiolucencies graded but no success criterion defined.

- Bone loss not greater than one-third of the vertical height of the bone.

- Gingival inflammation amenable to treatment.

- Functional service for 5 years in $75 \%$ of patients.

\section{Statistical Analysis}

Each variable was analyzed and $p<0.05$ was considered statistically significant. Data were analyzed by Statistical Package for the Social Sciences statistical software (IBM SPSS, version 10; Statistics, IBM, Armonk, USA).

\section{RESULTS}

A total of 260 patients were screened and out of 260 patients, 60 of those who did not meet the inclusion and exclusion criteria were excluded from the study. The sample size for this study was a total of 200 patients with 650 implants. Of 200 patients, 88 were males and 112 were females (Table 1 ). The success rate was $88.8 \%$, i.e., a total of 572 implants were successful with p-value of 0.414 (Table 2). A total of 78 implants were considered failures; out of 78 (Graph 1), 20 implants were surgically removed. Failed cases were divided into two categories: Early and late failure. In single risk factor group, a total of 28 implants

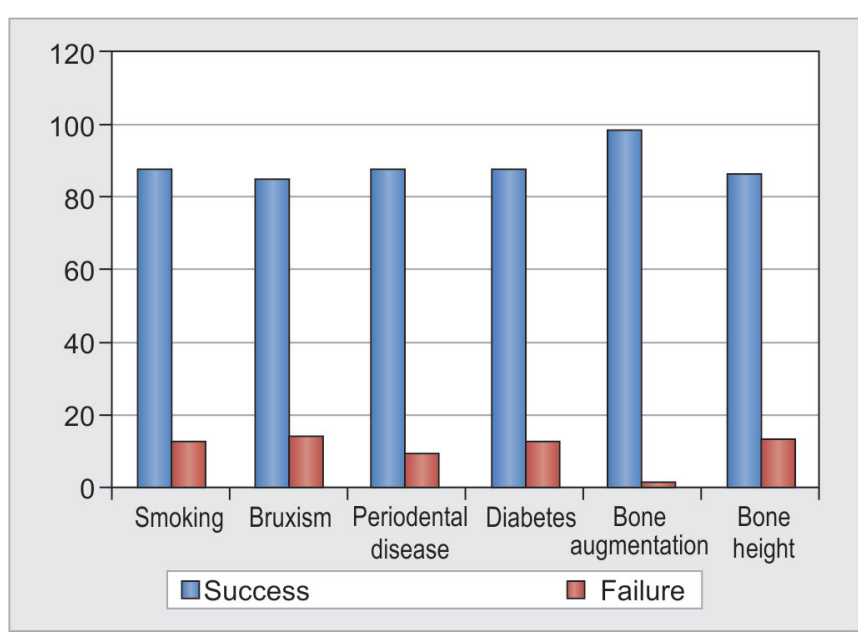

Graph 1: Success and failure factors 
Table 3: Analysis of multiple risk factors

\begin{tabular}{|c|c|c|c|c|c|c|}
\hline Groups & Patients & Implants & $\begin{array}{l}\text { Early } \\
\text { failure }\end{array}$ & $\begin{array}{l}\text { Late } \\
\text { failure }\end{array}$ & $\begin{array}{l}\text { Success } \\
(\%)\end{array}$ & $p$-value \\
\hline$A B$ & 25 & 88 & 3 & 2 & 94.3 & 0.360 \\
\hline$A C$ & 18 & 67 & 6 & 4 & 85 & 0.312 \\
\hline$A D$ & 22 & 45 & 5 & 5 & 77.7 & 0.296 \\
\hline$B C$ & 15 & 49 & 3 & 2 & 89.79 & 0.423 \\
\hline$B D$ & 5 & 10 & 1 & 1 & 80 & 0.445 \\
\hline$C D$ & 12 & 45 & 1 & 2 & 93.3 & 0.565 \\
\hline$A B C$ & 10 & 18 & 2 & - & 88.8 & 0.538 \\
\hline$A B C D$ & 9 & 12 & 1 & 1 & 83.3 & 0.497 \\
\hline ABCDE & 10 & 10 & 2 & 2 & 60 & 0.002 \\
\hline Total 2 & 116 & 345 & 24 & 19 & 87.5 & 0.039 \\
\hline Total & 200 & 650 & 52 & 26 & 88 & 0.543 \\
\hline
\end{tabular}

$p>0.05$, not significant

were considered as failure: Group $\mathrm{A}-12$ cases, group $\mathrm{B}-8$ implants, group $\mathrm{C}-4$, group $\mathrm{D}-5$, group $\mathrm{E}-1$, and group F-6 implants, whereas 6 cases were reported as late failure (Table 2). Implant therapy in patients with multiple risk factors was also divided as early and late failure. Fifty-two cases were reported as early failure and 26 cases as late failure (Table 3). Implant failure due to smoking and bruxism was significant in our study $(p<0.05)$. In multiple risk factors, group ABCDE showed a failure rate of $40 \%$, which is highly significant (Table 3 ); in our study, the early failure rate was more as compared with late failure. The failure rate was more in case of multiple risk factors than those of single risk factors.

\section{DISCUSSION}

The phenomenon of osseointegration of titanium implants was discovered by Brånemark, in 1952. Brånemark defined osseointegration as "a direct structural and functional connection between ordered living bone and the surface of a load-carrying implant. ${ }^{6 \prime}$ Implant success rate has been described by various authors in literature. Six years survival rate was reported by Charyeva et $\mathrm{al}^{7}$ with $96 \%$ success rate, whereas Simonis et al ${ }^{8}$ reported a success rate of $83 \%$.The difference in two studies could be due to follow-up period and patients' response. In our study, the success rate was $88 \%$ which was similar to Simonis et al's ${ }^{8}$ study.

In our study, the failure was divided into two stages: Early and late failure. The reason for early failures could be body's immune response or the occlusal load. ${ }^{9}$ However, late failure can be due to the long-term effect of habits, such as smoking, bruxism, or fracture. ${ }^{10}$ In this study, smoking and bruxism were the main single risk factors which lead to failure of implant. The possible reason behind is smoking interferes with wound healing, it irritates the soft tissue, and is also associated with bone loss, thus delays healing. ${ }^{11}$ Bruxism is a parafunctional habit which leads to wear of occlusal surface of teeth and further leads to loss in vertical dimension. It increases the load for temporomandibular joint and thus causes temporomandibular disorders. Thickness and height of the bone should be considered to prevent injury to adjacent tooth as well as other anatomical landmarks like maxillary sinus. The height and width can be measured by visual analysis and palpation. Hence, based on the success criteria, a total of 572 implants were considered successful and 78 implants were recognized as failure. Of 78 implants, failure due to smoking was in $12.83 \%$ $(\mathrm{p}<0.05)$ of cases, which is similar to the study conducted by Bain and Moy, ${ }^{12}$ who have reported a failure of $11.3 \%$ in smokers. Failure rate due to bruxism was $14.55 \%$ $(p<0.05)$, whereas in the case of multiple risk factors maximum failure was caused due to combination of group $\mathrm{ABCDE}$, i.e., $40 \%$, and group $\mathrm{AD} 22.23 \%$ (Table 3). The association of bruxism and smoking resulted in low failure rate $(5.7 \%)$. Failure due to bone augmentation was minimum, i.e., $1.62 \%$, which was similar to those reported by Busenlechner et al; ${ }^{13}$ however, when bone augmentation was in association with smoking, periodontal disease, and diabetes, its failure rate was $40 \%$, and p-value being 0.002 , which is highly significant. A study conducted by Salvi et $\mathrm{al}^{14}$ reported that poorly controlled diabetes is the reason for failure of implant. Infection of the oral cavity also causes implant failure; early sign of failure is peri-implantitis, which leads to inflammation of tissue around the osseointegrated implant which further leads to mobility, bone loss, and gingivitis.

McDermott et al ${ }^{15}$ stated that risk factors can be modified by the clinician for success of dental implant. Chuang et $\mathrm{al}^{16}$ suggested that modification of risk factors, such as tobacco use, immediate implants, and implant staging potentially may help in enhancing implant survival. Baig and Rajan ${ }^{17}$ in their review on risk factors on implant survival mentioned that smoking is one of the potential risk factors and it causes significant marginal bone loss around implant; they also concluded that failure rate in smokers is double than in nonsmokers. Karoussis et $\mathrm{al}^{18}$ compared the success and complication rates of implants between patients with periodontitis over teeth lost due to other reasons and observed lower success in patients with periodontitis in 10-year follow-up compared with teeth lost due to other reasons. Roccuzzo et a $\mathrm{l}^{19}$ compared the long-term success of implants in periodontally compromised over healthy ones and found lower success rate in patients with periodontitis with peri-implant bone loss. Romeo et $\mathrm{al}^{20}$ evaluated the survival rate of different implant-supported prostheses for mean of 3.85 years and observed cumulative implant survival rates for implants supporting single-tooth prostheses of $95.6 \%$, cantilever fixed partial prostheses for $94.4 \%$, fixed partial prostheses for $96.1 \%$, fixed complete prostheses for $100 \%$, implant/tooth-connected prostheses 
for $90.6 \%$, and overdentures for $95.7 \%$. Similar survival and success rates were documented for implants placed in maxillae and mandibles.

Bornstein et $\mathrm{al}^{21}$ did a study to evaluate risk factor of systemic disease and medication on implant failure in 250 patients. The cumulative implant survival rate for implants supporting single-tooth prostheses was 95.6\%, for cantilever fixed partial prostheses was $94.4 \%$, for fixed partial prostheses was $96.1 \%$, for fixed complete prostheses was $100 \%$, for implant/tooth-connected prostheses was $90.6 \%$, and for overdenture patients was $95.7 \%$.

Thus, patient's oral hygiene, health conditions, and various other risk factors should not be neglected before implant therapy.

\section{CONCLUSION}

The success of implant depends on patient selection, so the risk factors should be evaluated before treatment. As per this study, even a single risk factor affects the success rate, but multiple risk factors have immense contribution in failure of implant. In this study, smoking, bruxism, and bone height were the risk factors responsible for failure. Smoking in association with diabetes, bruxism, periodontal disease, and bone augmentation can lead to implant failure.

\section{REFERENCES}

1. Holm-Pedersen P, Loe H. Textbook of geriatric dentistry. 2nd ed. London: Wiley; 1997.

2. Bowen Antolín A, Pascua García MT, Nasimi A. Infections in implantology: from prophylaxis to treatment. Med Oral Patol Oral Cir Bucal 2007 Aug;12(4):E323-E330.

3. Lee JH, Frias V, Lee KW, Wright RF. Effect of implant size and shape on implant success rates: a literature review. J Prosthet Dent 2005 Oct;94(4):377-381.

4. Diz P, Scully C, Sanz M. Dental implants in the medically compromised patient. J Dent 2013 Mar;41(3):195-206.

5. Schnitman PA, Shulman LB. Recommendations of the consensus development conference on dental implants. J Am Dent Assoc 1979 Mar;98(3):373-377.

6. Brånemark PI, Adell R, Breine U, Hansson BO, Lindström J, Ohlsson A. Intra-osseous anchorage of dental prostheses. I. Experimental studies. Scand J Plast Reconst Surg 1969;3(2):81-100.

7. Charyeva O, Altynbekov K, Zhartybaev R, Sabdanaliev A. Long-term dental implant success and survival-a clinical study after an observation period up to 6 years. Swed Dent J 2012;36(1):1-6.
8. Simonis P, Dufour T, Tenenbaum H. Long-term implant survival and success: a 10-16-year follow-up of non-submerged dental implants. Clin Oral Implants Res 2010 Jul;21(7):772-777.

9. Esposito M, Hirsch JM, Lekholm U, Thomsen P. Biological factors contributing to failures of osseointegrated oral implants. (II). Etiopathogenesis. Eur J Oral Sci 1998 Jun;106(3):721-764.

10. Clark D, Levin L. Dental implant management and maintenance: how to improve long-term implant success? Quintessence Int 2016;47(5):417-423.

11. Chrcanovic BR, Albrektsson T, Wennerberg A. Bruxism and dental implants: a meta-analysis. Implant Dent 2015 Oct;24(5):505-516.

12. Bain CA,Moy PK. The association between the failure of dental implants and cigarette smoking. Int J Oral Maxillofac Implants. 1993;8(6):609-15.

13. Busenlechner D, Fürhauser R, Haas R, Watzek G, Mailath G, Pommer B. Long-term implant success at the academy for oral implantology: 8-year follow-up and risk factor analysis. J Periodontal Implant Sci 2014 Jun;44(3):102-108.

14. Salvi GE, Carollo-Bittel B, Lang NP. Effects of diabetes mellitus on periodontal and peri-implant conditions: update on associations and risks. J Clin Periodontol 2008 Sep;35 (Suppl 8):398-409.

15. McDermott NE, Chuang SK, Woo VV, Dodson TB. Complications of dental implants: Identification, frequency, and associated risk factors. Int J Oral Maxillofac Implants 2003 Nov-Dec;18(6):848-855.

16. Chuang SK, Wei LJ, Douglass CW, Dodson TB. Risk factors for dental implant failure: a strategy for the analysis of clustered failure-time observations. J Dent Res 2002 Aug;81(8):572-577.

17. Baig MR, Rajan M. Effect of smoking on the outcome of implant treatment: a literature review. Indian J Dent Res 2007 Oct-Dec;18(4):190-195.

18. Karoussis IK, Salvi GE, Heitz-Mayfield LJ, Brägger U, Hämmerle $\mathrm{CH}$, Lang NP. Long-term implant prognosis in patients with and without a history of chronic periodontitis: a 10-year prospective cohort study of the ITI Dental Implant System. Clin Oral Implants Res 2003 Jun;14(3):329-339.

19. Roccuzzo M, De Angelis N, Bonino L, Aglietta M. Ten-year results of a three-arm prospective cohort study on implants in periodontally compromised patients. Part 1: implant loss and radiographic bone loss. Clin Oral Implants Res 2010 May;21(5):490-496.

20. Romeo E, Lops D, Margutti E, Ghisolfi M, Chiapasco M, Vogel G. Long-term survival and success of oral implants in the treatment of full and partial arches: a 7-year prospective study with the ITI dental implant system. Int J Oral Maxillofac Implants 2004 Mar-Apr;19(2):247-259.

21. Bornstein MM, Cionca N, Mombelli A. Systemic conditions and treatments as risks for implant therapy. Int J Oral Maxillofac Implants 2009;24 (Suppl):12-27. 